\title{
Conservation of the Church and the Friary of "Santa Maria degli Angeli" in Atella (Potenza, Italy)
}

\author{
Filiberto Lembo, Francesco Paolo R. Marino, Carmela Cancellara \\ School of Engineering, University of Basilicata, 85100 Potenza, Italy \\ E-mail: filiberto.lembo@unibas.it; francesco.marino@unibas.it
}

Received: 28 July 2017; Accepted: 2 October 2018; Available online: 25 November 2018

\begin{abstract}
Built at the end of XV century and re-built in XVIII, as a consequence of many earthquakes, englobing the precious portal of a previous church of XIII, the complex set up by the Church of Santa Maria degli Angeli and the Friary of Minor Friars, expropriated by the unitary Italian State after 1860 and sold to private peoples, had a destiny common to many similar buildings in the south of Italy, becoming farm and agricultural products' warehouse. Struck again by the earthquake of 1980, it has been the object of partial safeguard works, but is now abandoned and in ruin. Because of its strategic position, in a context very rich of environmental and historicalcultural goods, it could be easily restored and intended to be a youth hotel, fulfilling an investment of great value for the development of the regional culture and economy. Research done through the careful architectural and technological survey of existing building and the design of low-technology works of conservational reconstruction and structural-functional update, demonstrates the feasibility of hypothesis and its sustainability.

Keywords: conservation of heritage; structural and functional update of heritage; low-technology systems; Quercus Cerris modified glued laminated timber.
\end{abstract}

\section{Introduction}

The Church and the Friary of Santa Maria degli Angeli are located in the center of southern Italy, in the Vitalba valley, under the Mount Vulture forests, about $1 \mathrm{~km}$ from the historic town of Atella, $512 \mathrm{~m}$ above sea level, founded by the Angevins between 1320 and 1330, such as Martina Franca and Francavilla Fontana (both in 1310) (see Fig. 1). The city, with a chessboard plant, still retains the remains of its castle, and in particular a tower (see Fig. 2) identical to those of Ostuni or of Martina Franca's town wall (cfr. Lembo, 1992) [1]).

Even before, there was a village in which there was a church, Santa Maria di Rivonigro, mentioned in a papal bull of 1152 by pope Eugene III, to which it could belong the lancet portal with zigzag-shaped frame of the 13th century, adorned by two capitals "of which we will find the models in the Lagopesole castle" (Bertaux, 1897) [2], which today is proudly displayed on the Eastern front of the Friary in question (see Fig. 3).

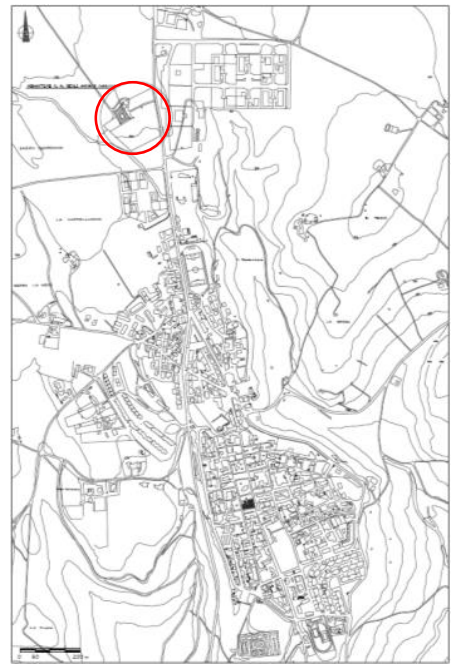

Figure 1: Church localization

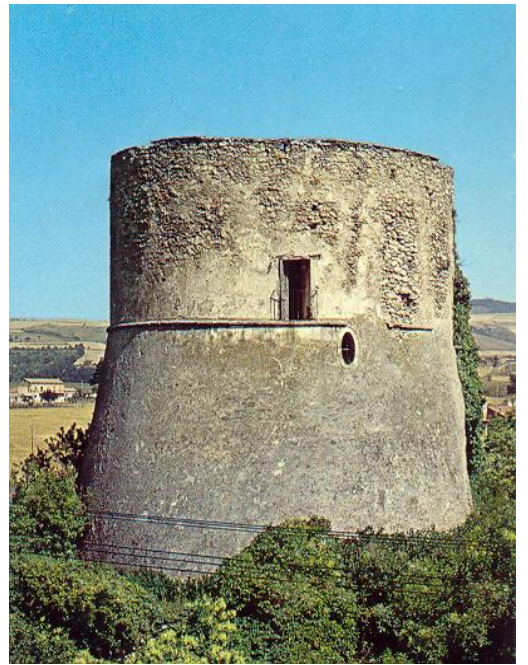

Figure 2: Castle's tower

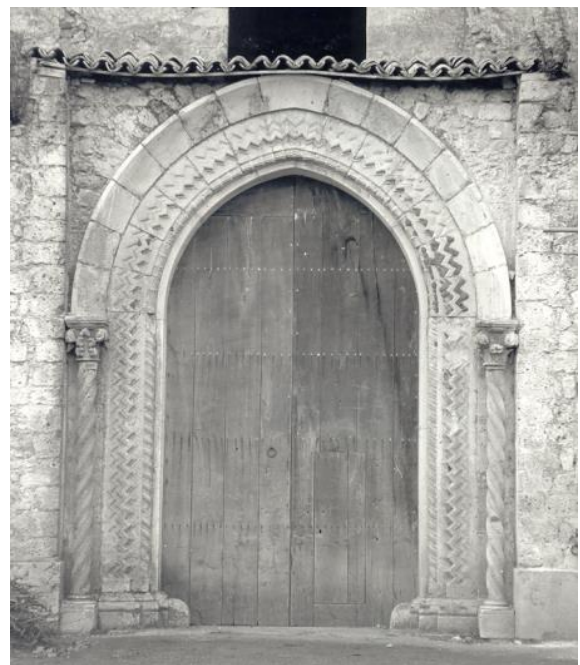

Figure 3: Lancet portal of the Friary 
But it was from 1330 on that, due to the tax exemptions offered by John of Anjou, the sixth son of Charles II, the city developed, becoming, between the fifteenth and sixteenth centuries, the most important city of this part of Southern Italy; as such, it was the subject of a plundering in 1496 by the French troops and of a siege and conquest by the Aragonese in 1502. It is around this historical moment (between 1463 and 1506) that moved to this place, where there already existed a (smaller) Church of Santa Maria degli Angeli, the Friary of Observant Friars, which was founded in 1439 under the title of Santa Maria di Vitalba, on a site downstream, unhealthy and malaric, and was took in a building which was hit by the 1456 earthquake. The Friary was later abandoned in 1652 , following the pope Innocent X bull Instaurandae regularis disciplinae, which decided the suppression of the institutes that housed less than six monks, and again hit by other earthquakes in 1688 and 1694. The Friary then saw the return of the fathers of the Order of Friars Minor Reformed in 1706, after the first hasty repairs, and from that time the building was deeply restored and expanded, assuming the actual appearance. From the comparison of the two available descriptions, one of 1642 and the other of 1723, it is clear that previously both the Friary and the Church were smaller (in particular the Church had only one nave); that the intermediate floors of the Friary and the cover of the Church were in wood and not vaulted, and that the Church was at that time (1723) under reconstruction: "the church is currently being built". All the religious Orders of the Kingdom of Naples were abolished in 1808 by decree of Gioacchino Murat and forfeited to the state goods, to be then sold to private persons. On this occasion an inventory was made, kept at the State Archives of the City of Potenza (Ecclesiastical Affairs, Cart. 1282) attesting to the existence (see Draw. 1) "of the sacristy, chorus, church with eight altars all well-decorated, five confessionals and a ten-member organ, a bell tower with two bells, a wellkept cloister, a warehouse, a kitchen, a refectory, a cellar. In the upper floor (see Draw. 2) there are twenty-six cells for playing host to the friars, of which six are without furnishings; in the last one is allocated a rich library of 325 books exposed in six bookcases."

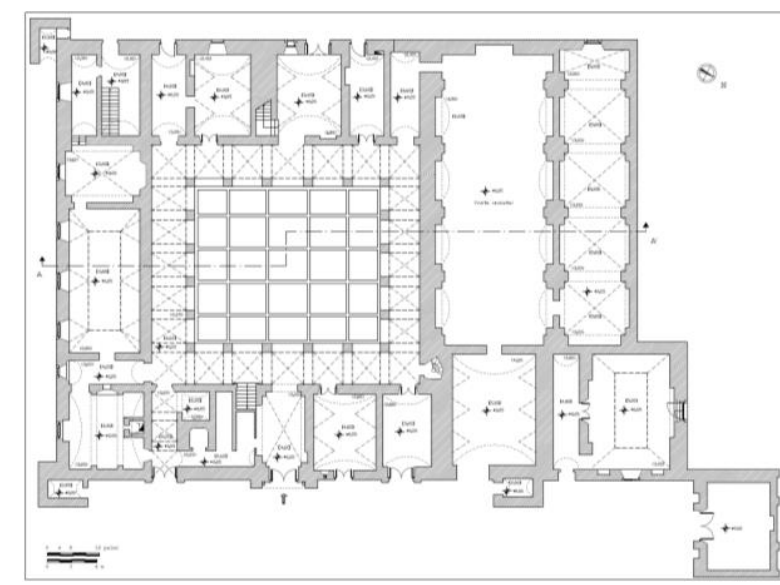

Drawing 1: Ground floor plan

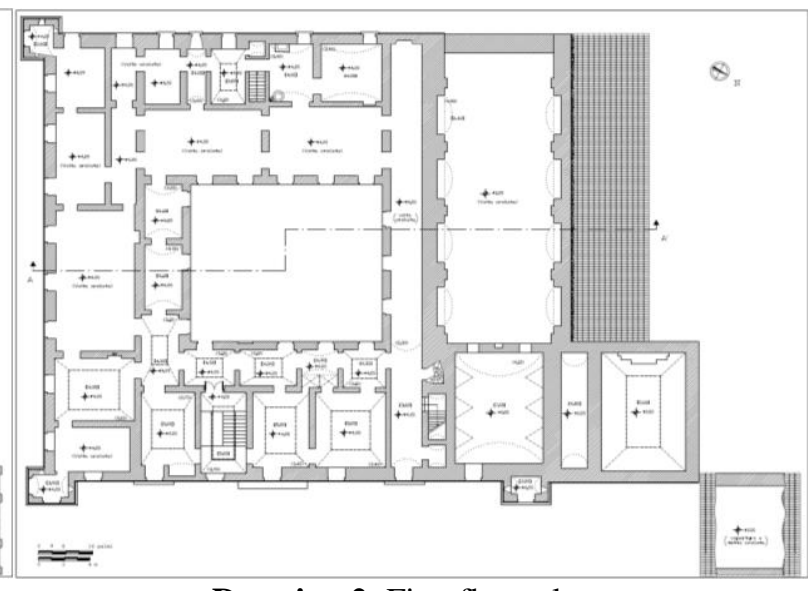

Drawing 2: First floor plan

Reactivated in 1816 with the return of the Borboni, the Friary and Church complex suffered the earthquakes of 1851 and 1857 and again in 1860 the expropriation from the new unitary state, like all ecclesiastical properties. It was put for sale, and it was bought by family De Martinis from the nearby town of Rionero in Vulture, to go on to the properties of the family Catena. Today it belongs to a private company. Intended to be the shelter of agricultural materials and vehicles, it was subjected to heritage protection legislation in 1913, according to Law 20/06/1909, no. 364; it still suffered the earthquake of 1930 and then that of 1980 , after which it was again subject, in 1983, to the heritage protection legislation referred to Law 01/06/1939 no. 1089, and has been subject to a safeguard intervention by the Superintendence for Environmental and Architectural Heritage of Basilicata, limited to the central part of the eastern wing, which has harnessed the covering vaults with reinforced concrete caps. As has been said, the building is currently completely abandoned, from several tens of years.

\section{Description of the building and its current conditions}

The building complex respects the typical provisions of the Franciscan Friary (Ministry of BB.CC.AA. BASILICATA, 1988) [3]) both as to the planned activities (the capitular hall, present in the models typical of other Orders, is missing), and as to their arrangement around the central courtyard.

The Church presents the small side nave, added from the late 16th century to deal with the theological instances emerging from the Council of Trento (1545-1563). The bell tower did not survive, documented as it 
was seen in 1808 (which perhaps stood on the quasi-isolated volume on the ground floor in the north-east corner, if it adheres to the representation present in a 1770 drawing [see Fig. 4]). It is characterized by three angular little towers with toroidal horizontal cornice and slanted basement, which reinforce its volumetric impact and give it the appearance of a fortified residence (see Fig. 5); by the wide windows of the "Roman" type (which in the towers have a lancet upper ending - a Gothicism that renews the formal articulation of the already mentioned beautiful entrance portal of the Friary, objet trouvé of the thirteenth century) (see Fig. 6 and 7); and by the top cornice, who has very strong light and shade effects, on the southern and eastern outlying facades and in the courtyard (see Figures 8 and 9).

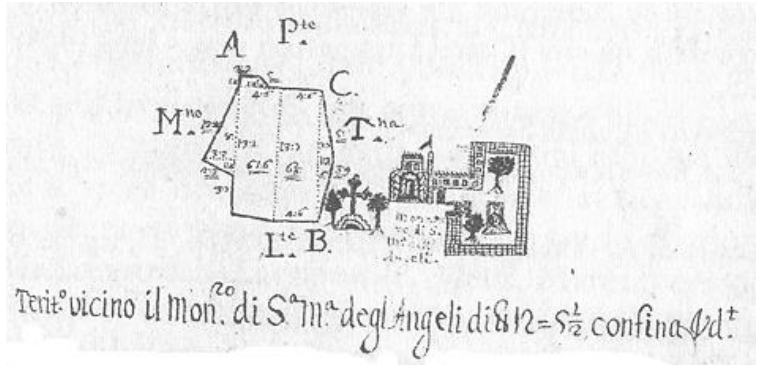

Figure 4: Friary building, drawing of 1770

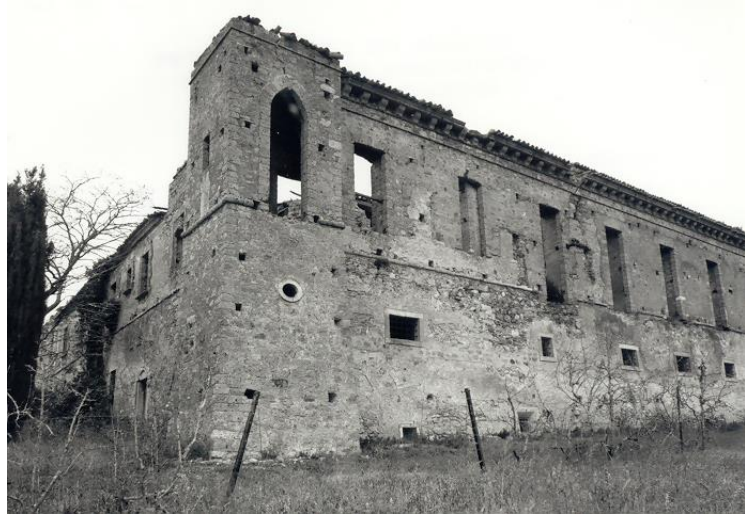

Figure 6: South-West tower of the Friary

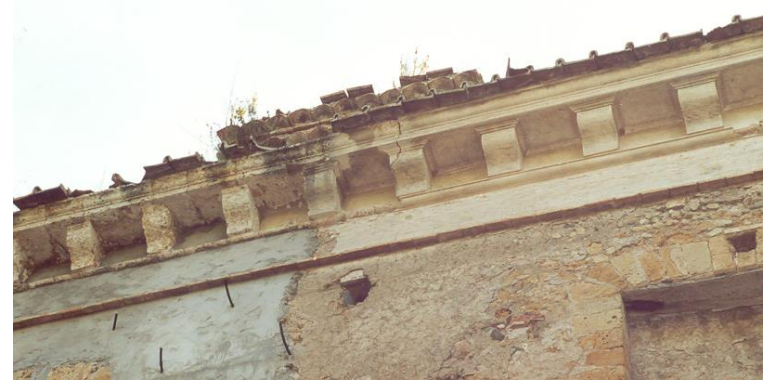

Figure 8: Friary, cornice on the main prospect

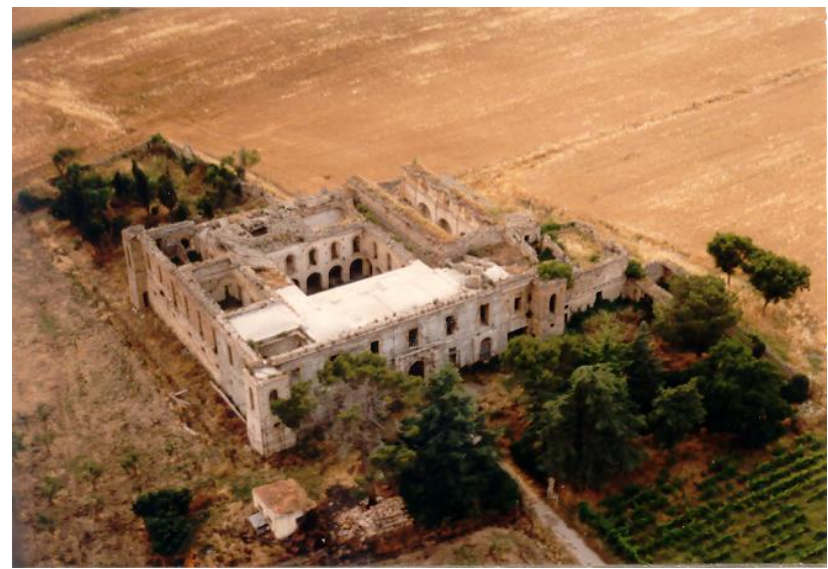

Figure 5: Friary building, aerial view

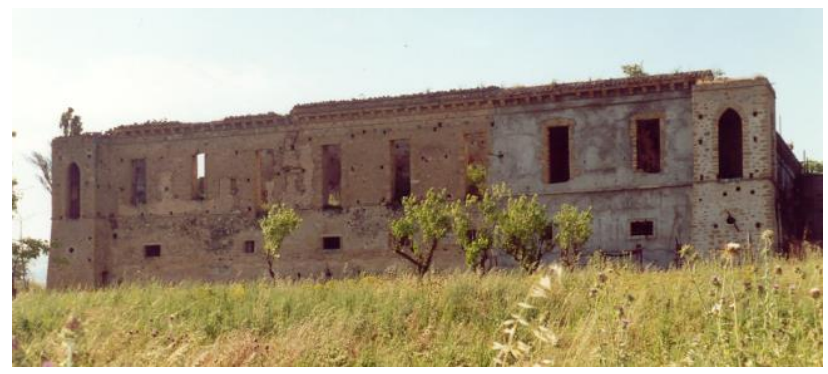

Figure 7: South side view of the Friary

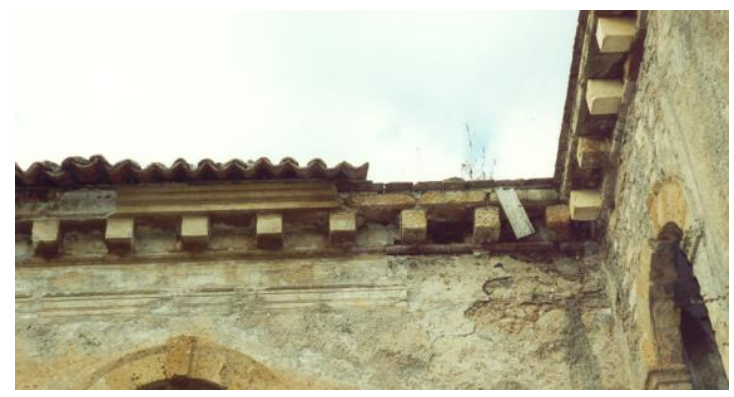

Figure 9: Detail of the cornice inside the cloister

The less important elevations, the northern and western ones, have the facades crowned by two rows of elegant "romanelle" (bent tile overhanging) (see Fig. 10 and Draw. 3). The cloister is well preserved (see Figg. 11 and 12), although the pillars have vertical crushing lesions (see Fig. 13a, on the left). The vaults that have been preserved on the ground floor are in good condition (see Fig. 13b, in the center), except that of the refectory, which is collapsing and therefore provided with props (see Fig. 13c, on the right). The vault of the main nave of the Church collapsed a long time ago (see Fig. 14a, on the left), as well as that of the northeastern room, which has been said to be possibly the base of the bell tower. 


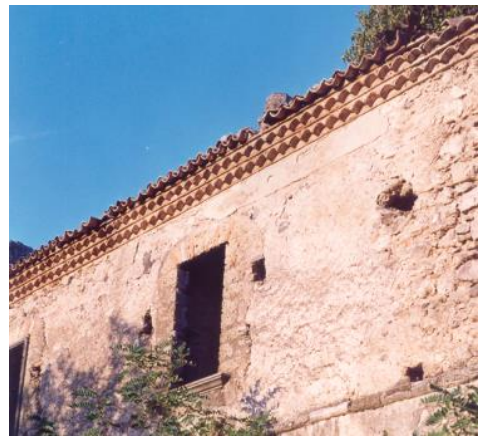

Figure 10: "Romanelle"

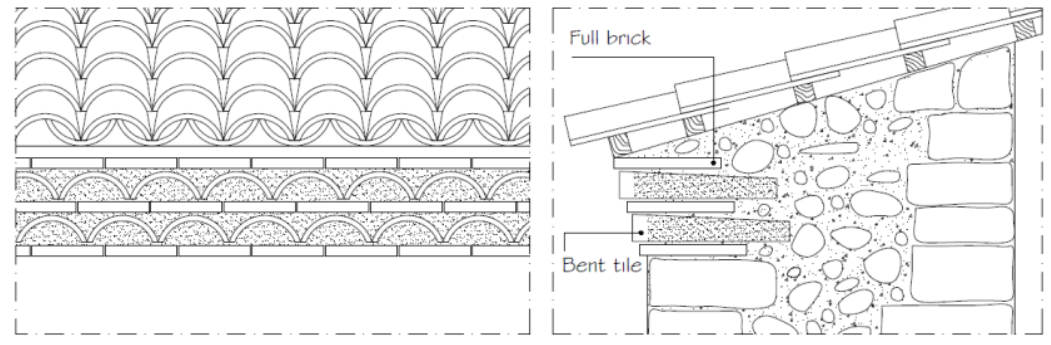

Cross section

Drawing 3: Bent tile overhanging on two rows placed on the gutter line
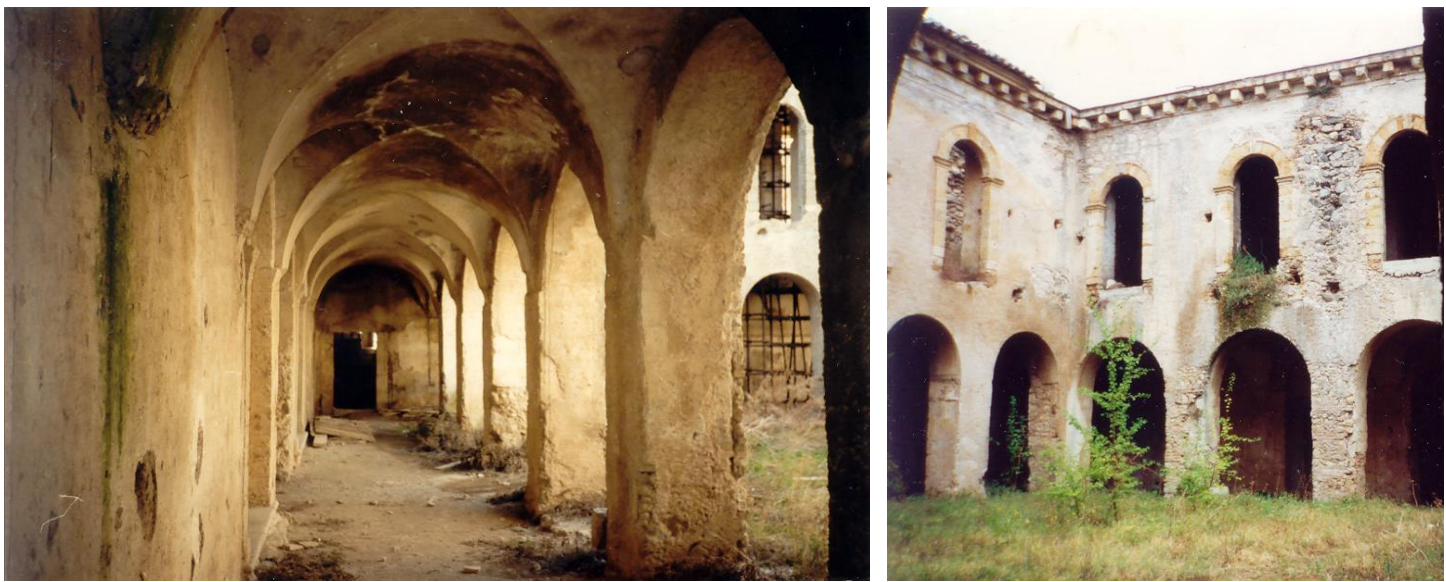

Figure 11: Cloister

Figure 12: East wing loggia
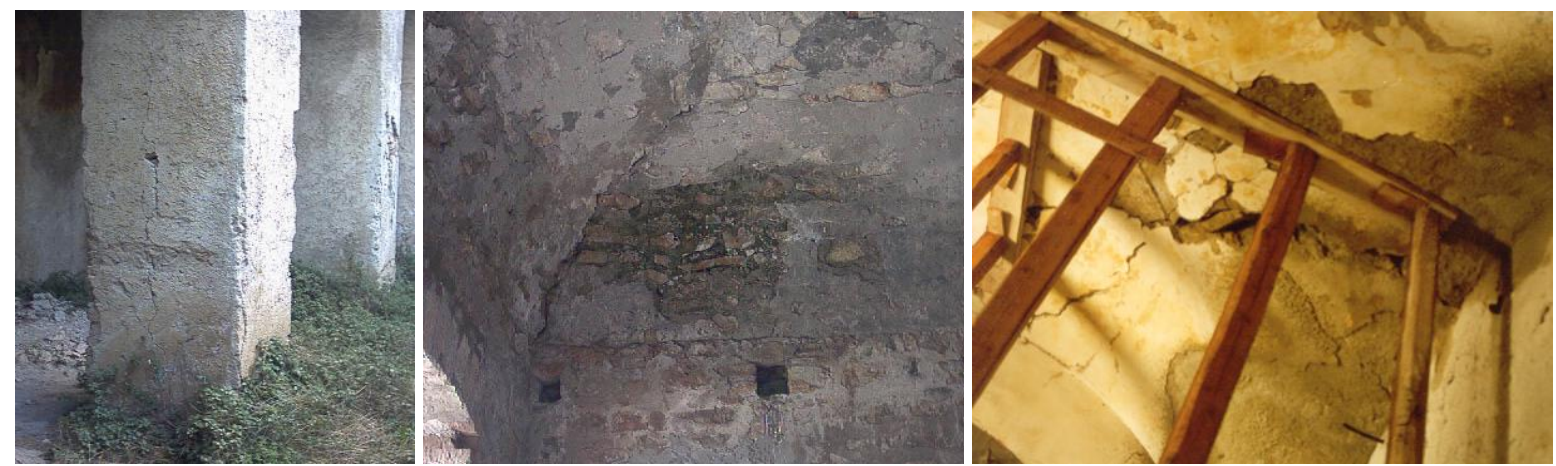

Figure 13: Degradation of the cloister's structures: pillar damaged by crushing (on the left); vaults remaining at the ground floor (in the center); vaults nearly collapsed (on the right)

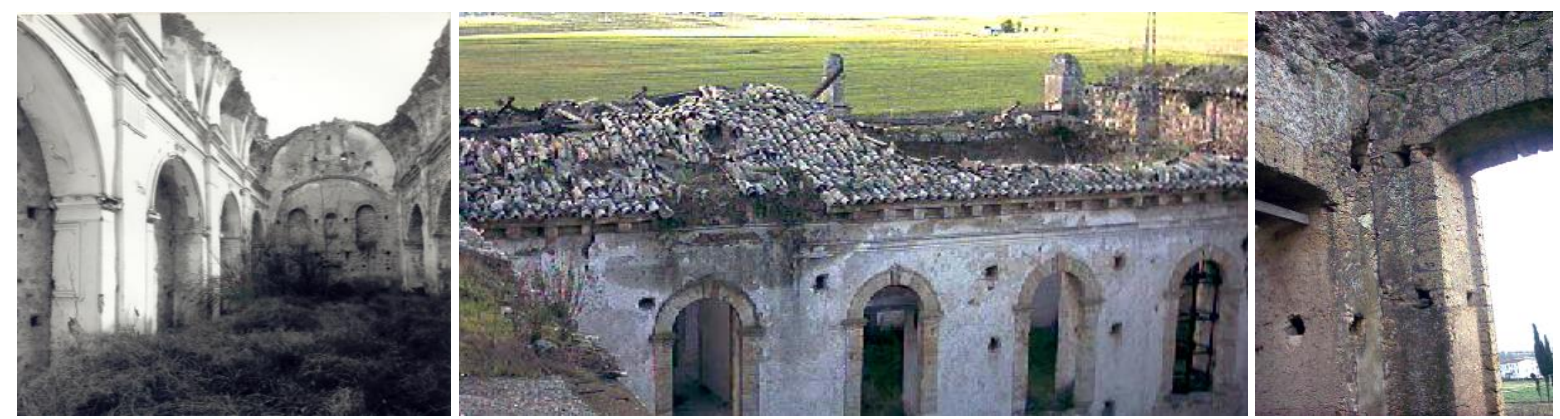

Figure 14: Conservation status of the Church of the Friary: internal view (on the left); ruins of ancient roofing, now collapsed (in the center); detachment of the internal walls from façade walls (on the right) 
On the first floor, all the vaults of the southern and western wing that have not been the subject of safeguard works after the earthquake of 1980, collapsed (see Fig. 14b, in the center) and there are vertical lesions between internal and external walls (see Fig. 14c, on the right). Ultimately, at present, the building is just over a picturesque ruin (see Draw. 4 and 5) that covers, at ground floor, 1.612 sq. m; and at first floor, 890 sq. m.

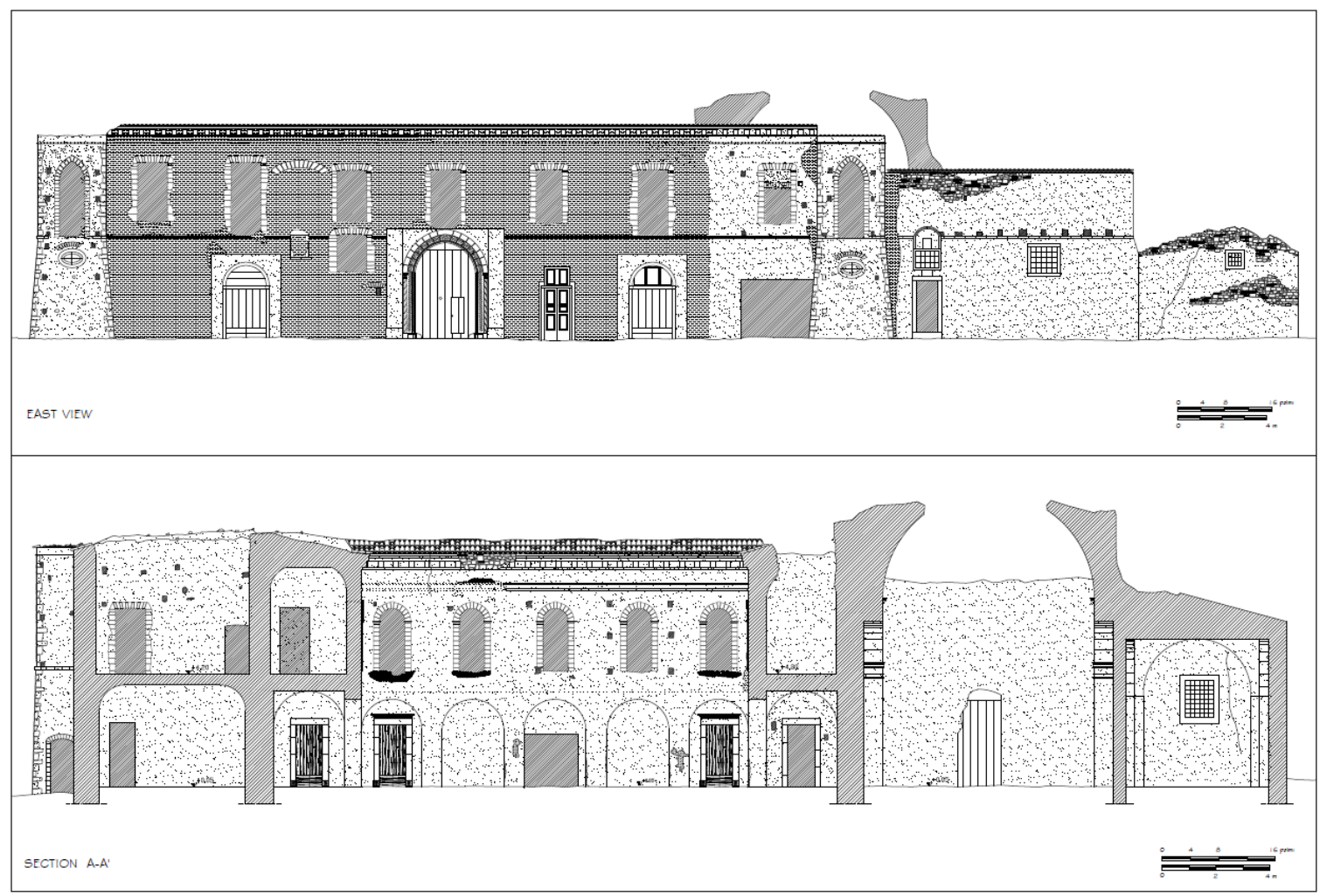

Drawing 4: East view and cross section

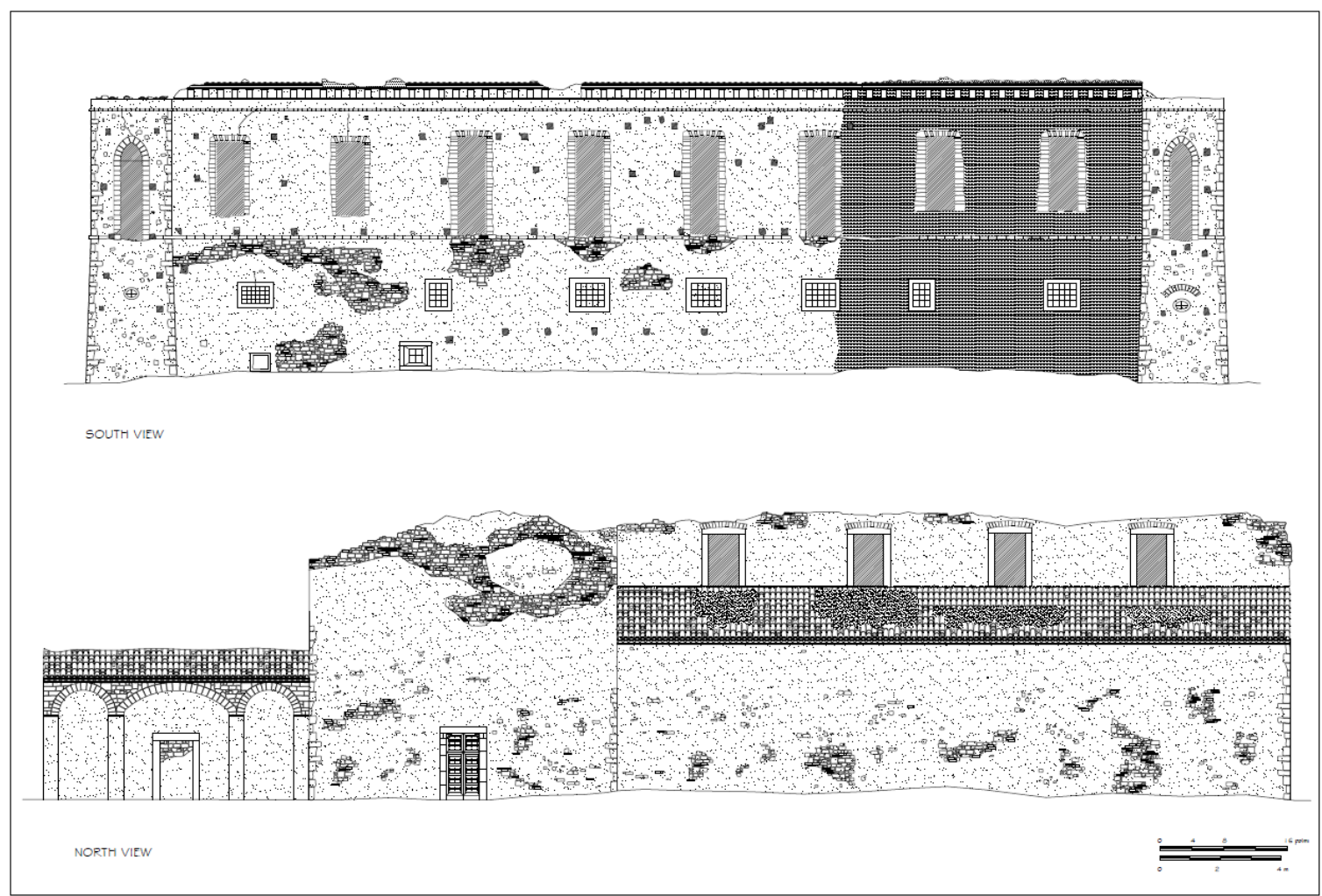

Drawing 5: South and North view 
Nevertheless, its meaning (Marconi, 1999) [4]) remains perfectly perceptible, both by the substantial integrity of the surrounding landscape (see Fig. 15) and of the architectural organism, and by the survival of much of its material culture, and therefore, of the story itself, which has expressed it: starting with the entrance portal (see Fig. 16), with its plaster decorations and still understandable color, of a beautiful cream and white, evidently the same as the building, which was all plastered and colored (a good lesson for those who still support the kitch of the uncivilized débadigeonneurs); to continue with the simple and elegant designs of the courtyard (see Fig. 17) and the stable (see Draw. 6) floors; with molded limestone stairs (see Fig. 23 and Draw. 7); with limestone thresholds of windows and doors-window "to the roman" (see Fig. 18 and Draw. 8); with the chestnut doors of access to the Rosary Chapel (see Draw. 9) and to the upper floor (see Draw. 10); with the windows of the refectory, and its non-removable grates, inserted and plunged in the limestone cornices at the time of the realization of the walls (see Draw. 11); and even the clay tubuli for collecting rainwater and for sewage (see Draw. 12 and Fig. 19), of unusual length.

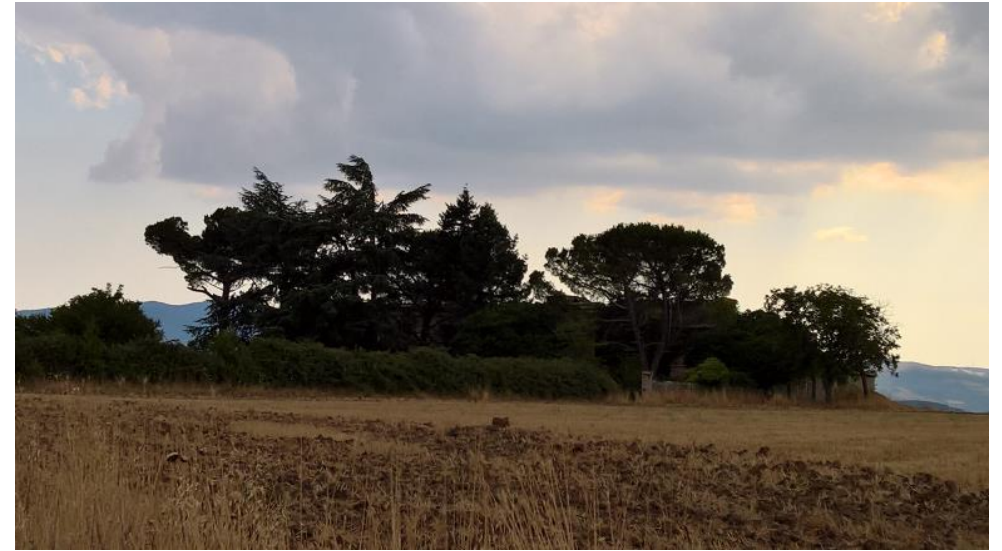

Figure 15: The Church and the Friary in the surrounding landscape

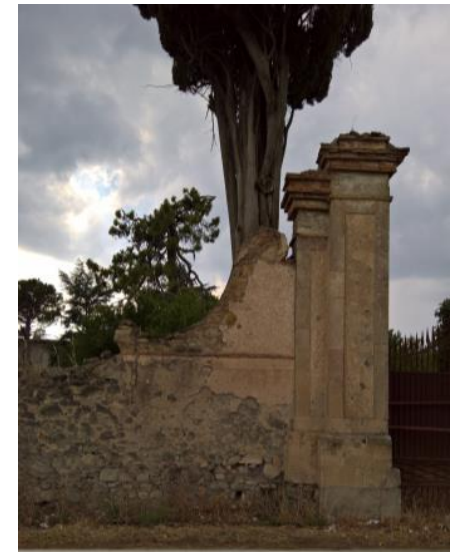

Figure 16: the left half of the entrance portal
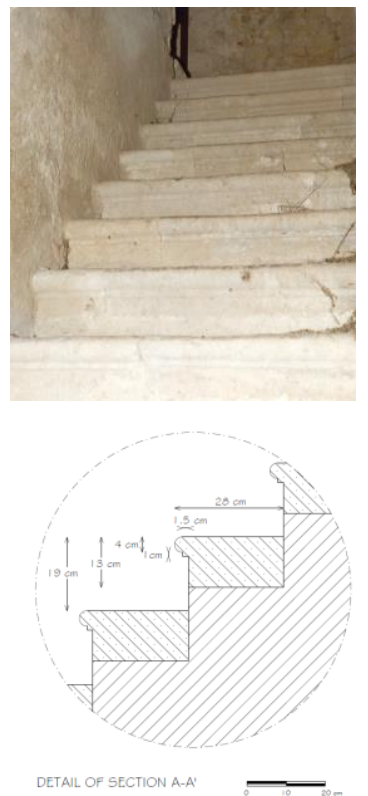

Drawing 7: molded limestone stairs

\section{Objective of research}

With regards to the charm of the building complex, the eloquent signs of its history from the thirteenth century to today and the quality of its proportional composition, its typological and formal organization and its colors in relation to the landscape, it is wanted to verify the possibility and the sustainability of its restoration, in order to 
make it back to being, as in the past, a strong element of promoting the culture and economy of local society.

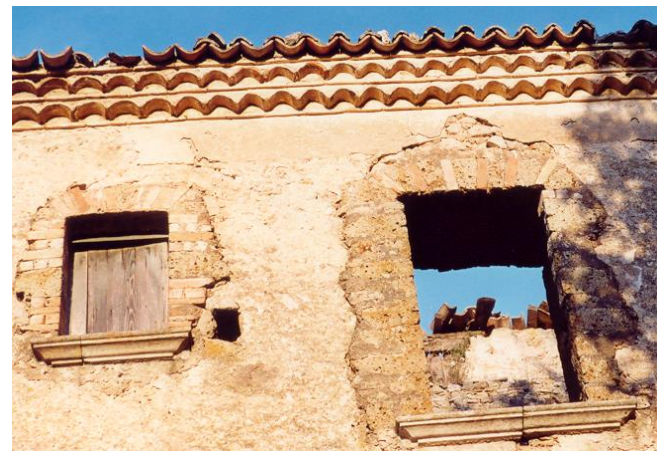

Figure 18: Limestone thresholds existing on the west prospect

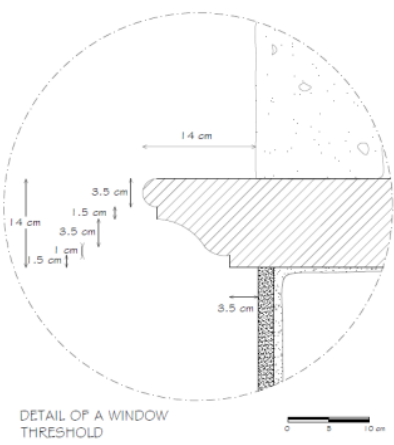

Drawing 8: Detail of a window threshold

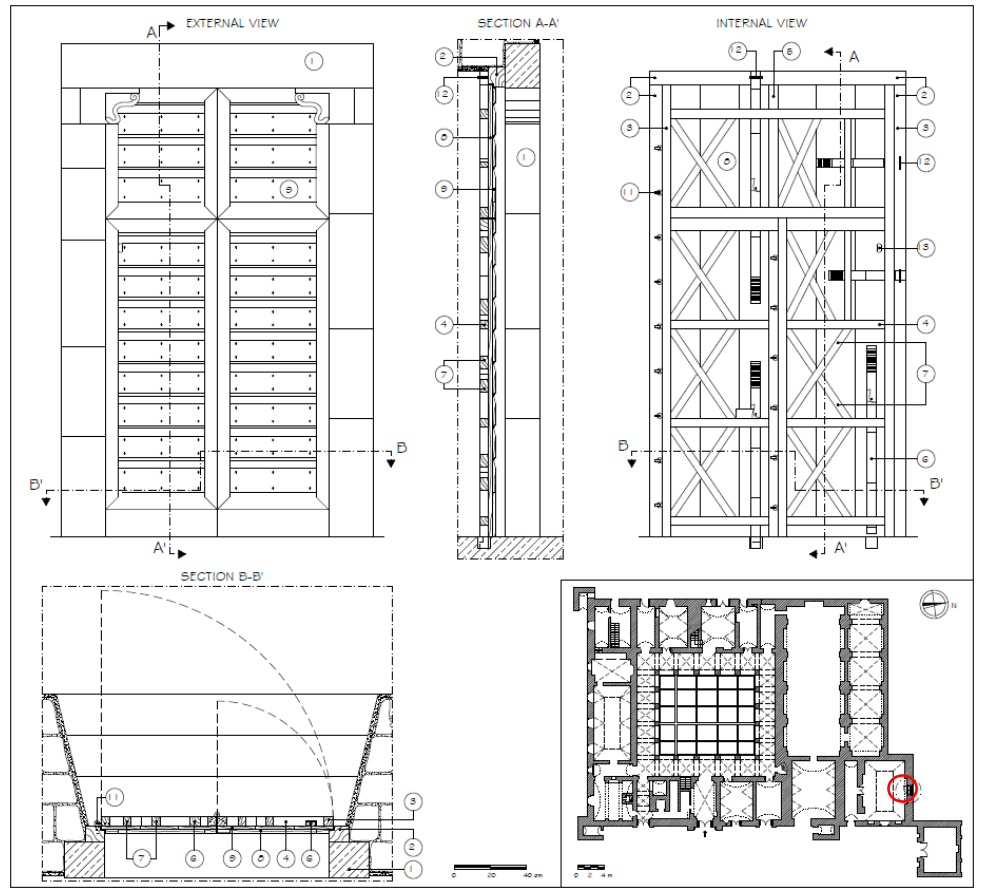

Drawing 9: Double-sided door, access to the Rosary Chapel

(Legend: 1 - limestone portal; 2 - case; 3 - mobile frame; 4 - frame cross member; 5 - brace; 6 - bar;

7 - stiffening elements; 8 - vertical planks; 9 - horizontal molded planks; 10 - lock;

11 - hinge (nail molded to ring); 12 - pin leaded between case and limestone portal)

\section{Reuse, Reduce technology, Recycle spaces, structures, material, forms, colors: new cultural approach}

Granted that, obviously, no destination compatible with original one could justify from a solely marketeconomistic point of view the cost of restauration, which must of necessity to sweep from re-construction by anastilosi of the collapsed parts, to the strengthening of the existing walls with colloidal lime grouts and to safeguard vaults with tie beams, to rebuilding of civil works and to new plants, it is plain as well that a careful benefits-costs evaluation, which assesses the impact of this intervention on regional strategies in long term, can justify an investment, necessarily public, which create value from the potential vocation of this building complex as attractor and multiplier of activities.

A Country who has dear to his bosom its own environmental and cultural heritage, just through intervention on such heritage can base a significant part of the objectives of growth, not only economic, but above all civil and cultural. 


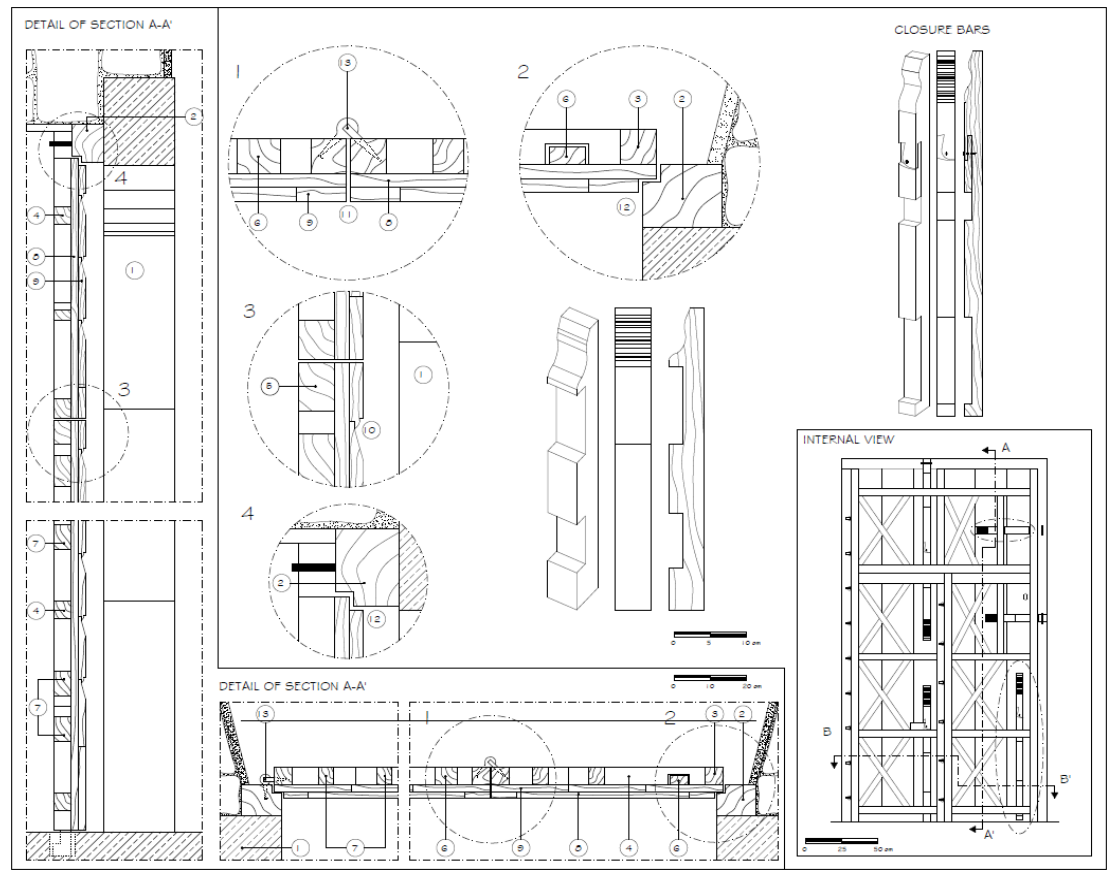

Drawing 10: Double-sided door, access to upper floor

(Legend: 1 - limestone portal; 2 - case; 3 - mobile frame; 4 - frame cross member; 5 - upper frame cross member of little door; 6 - bar; 7 - stiffening elements; 8 - vertical planks; 9 - horizontal molded planks;

10 - molding; 11 - butt joint; 12 - rebated joint)

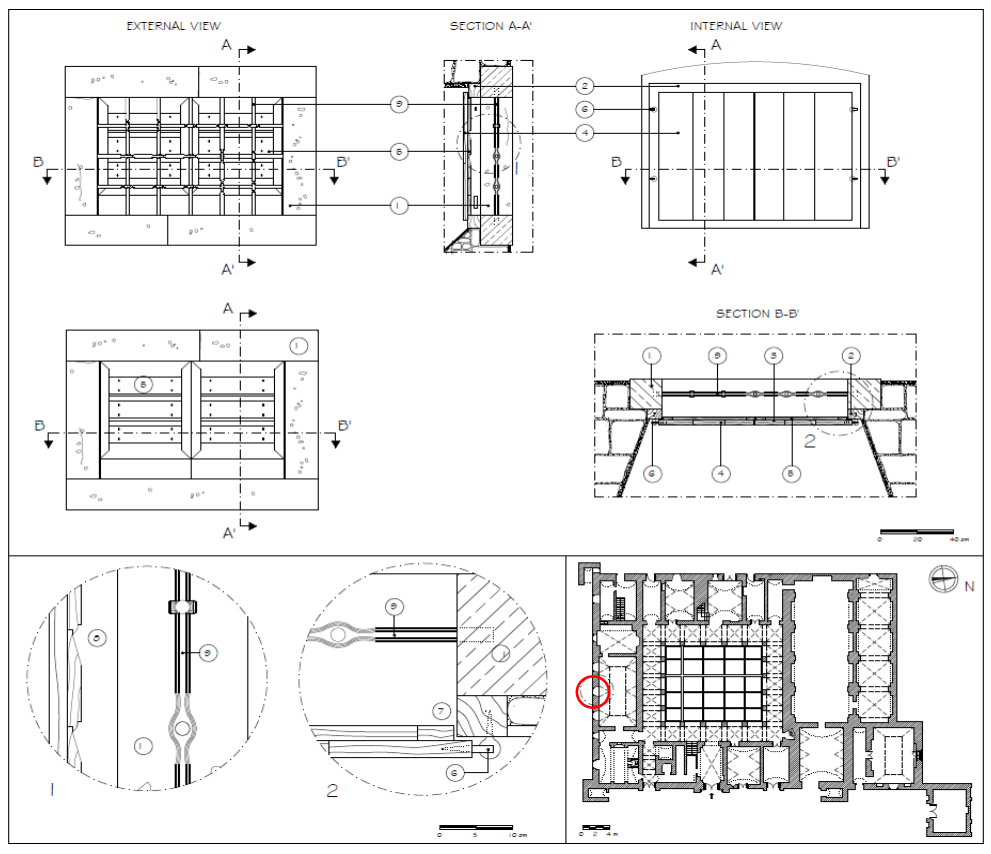

Drawing 11: Windows of the refectory, with its non-removable gratings

(Legend: 1 - limestone cornice; 2 - case; 3 - mobile frame; 4 - vertical planks; 5 - horizontal molded planks; 6 - hinge (nail molded to ring);7 - rebated joint; 8 - molding; 9 - grate in round iron (Ø $20 \mathrm{~mm})$

In the perspective of an economy low-carbon and characterized by the happy de-growth, the territory which surrounds Atella is one of the richest for the beauties of landscape, history and archeological - monumental sites of the South of Italy. $19 \mathrm{~km}$ away there are in the direction north woods, mineral waters and lakes of Monticchio on the mountainside of Vulture volcano; in the direction south-west woods, falls and il Ottone I's castle in S. Fele; $15 \mathrm{~km}$ away castles of Ruvo del Monte and Lagopesole; $17 \mathrm{~km}$ away that of Ripacandida (Palazzo Chiari); 
$27 \mathrm{~km}$ away these of Melfi and Venosa; $30 \mathrm{~km}$ away that of Lavello; $50 \mathrm{~km}$ away these of Monteverde, Ascoli Satriano, Palazzo S. Gervasio; 60-65 km away these of S. Agata di Puglia, Minervino Murge and Savoia di Lucania; 70-75 km away these of Canosa, Garagnone, Monte Serico, Satriano, Brienza: everyone place dear to the Longboard, Normand and Frederic's epics (Licinio, 2010 [5]). Not mentioning of the next Capitanata, with multiple fences of castles round Foggia, reorganized by Frederic the II (Leistikow, 1989 [6]).

Against all these testimonies, inserted in a context not only of landscape, but also eno-gastronomic of excellence, it lacks completely a supply of core touristic services. The unique Youth Hotel in Basilicata is in Matera, $120 \mathrm{~km}$ away, at the same distance of the nearest of the 11 Youth Hotels which are in Puglia, that of Bisceglie. It exists therefore a broad potential market of core touristic services for the young peoples, who constitute more active segment of the market, which tends to replicate in the time the presence and to spread the communication.

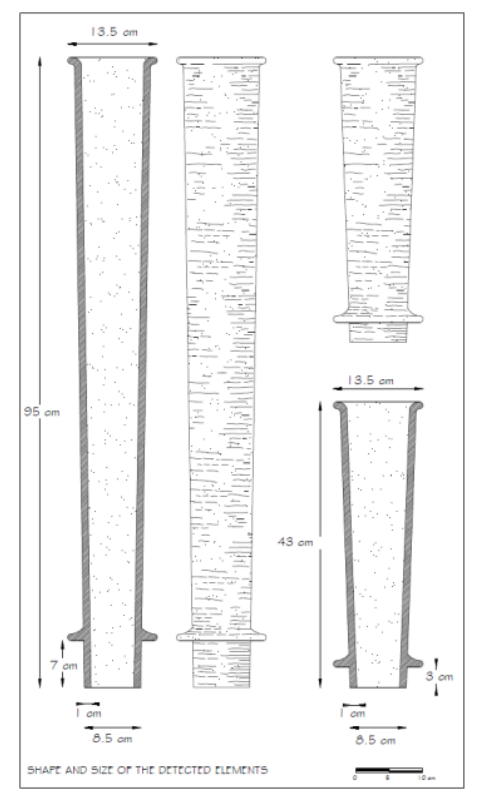

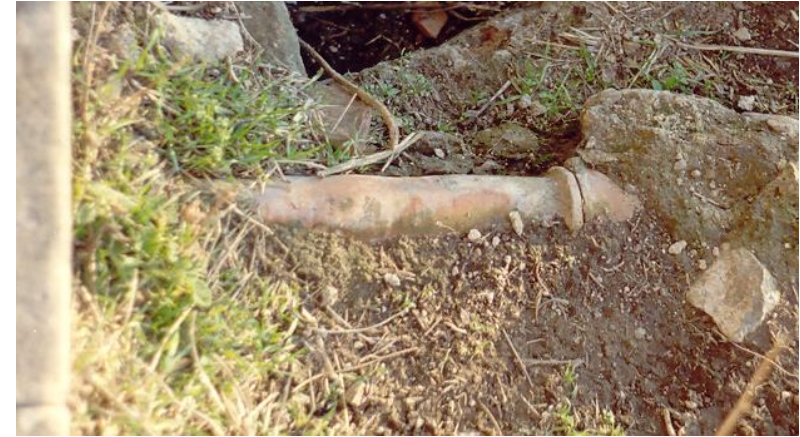

Figure 19: Clay tubuli for collecting rainwater and for sewage, of unusual length.

Drawing 12: Waste water elements, clay pipes (tubuli)

\section{The conservation design}

The conservation design of the building has intended that his stato normale [normal state] (which Decreto and Circolare Fiorelli 1882) (Marconi 1999 cit., pag. 50 [2]) is that the middle years of eighteenth century and previews the reconstruction by anastilosi of the collapsed vaults, according to the constructive traditional techniques, with vaults in local tuff and roof in Oakwood (Quercus Cerris L.) of local forests, termohigrometrically conditioned and glued laminated (Lembo \& Marino, 2008 [7]) (see Draw. 13).

At ground floor, destination of the spaces of the Friary has been confirmed (see Draw. 14): the entrance continues to take place through the wonderful portal of XIII century, which sides are front-office, back-office and wardrobe; a lift is inserted discreetly in a room existing. The space where Friars had livable fireplace becomes a tavernetta [little tavern] to 15 peoples and refectory becomes a restaurant to 45 peoples with relating kitchen, where was the previous, linked to the washing area to the existing cellar below. West aisle is occupied by the apartment of daddy hotelkeeper, by a room for TV e by toilet facilities. Church, restored in his volume, but with a simple acoustic render, without stucco, in the rebuilt part, becomes reading and multimedia room in the choir and polifunctional room (conferences, shows) in the principal nave, preceded by a bar - foyer, whereas the small side nave becomes a little lounge and toilet facilities. Rosary Chapel remains the same, and room hypothesized as the bell tower base becomes deposit for bicycles and motorcycles.

At the first floor (see Draw.15), accessible through the lift and two stairs, set on opposite sides of the cloister (west and east) it is confirmed previous destination, with dormitory, separate by sex, and relating toilet facilities. The plan provides for 23 female guests and 25 male guests.

The result is the complete conservation both of the matter, as of meaning of the building (see Draw.16).

Obviously, once indentified the target, has been verified that it was technically and economically feasible. 


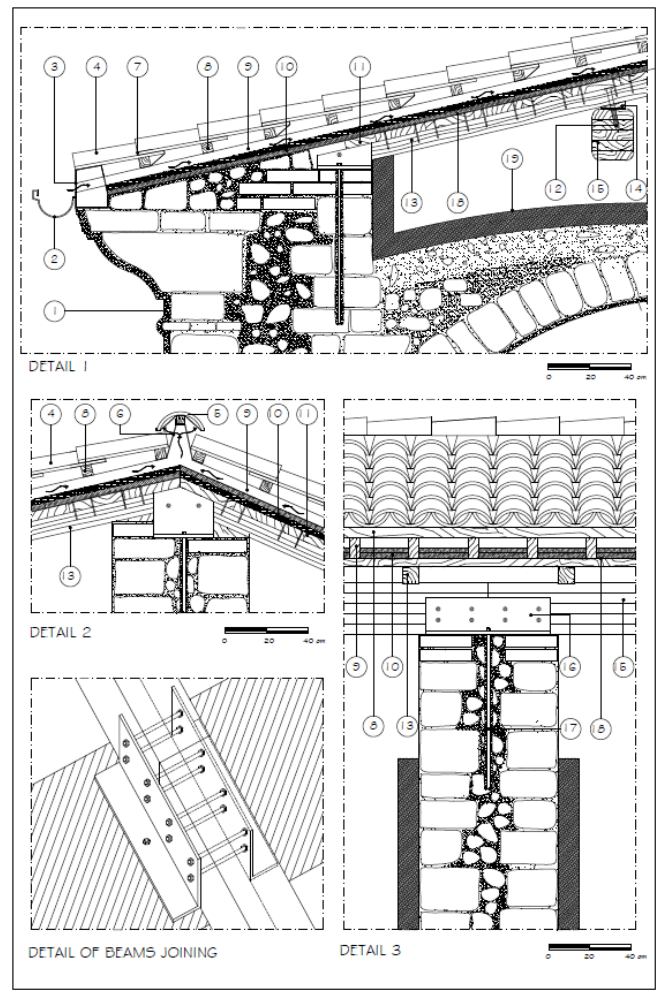

Drawing 13: Detail of roof in conditioned glued laminated Oakwood Quercus Cerris L.

(Legend: 1 - thermo-insulating render $(40 \mathrm{~mm}) ; 2$ - copper gutter $(10 / 10 \mathrm{~mm}) ; 3$ - copper mesh; 4 - bent tile; 5 - ridge cap; 6 wood and copper ventilation element; 7 - copper fixing element for bent tile; 8 - counter batten $(50$ x $50 \mathrm{~mm}) ; 9$ - batten $(50$

x $100 \mathrm{~mm}) ; 10$ - cork insulating panels (30 + $30 \mathrm{~mm}$ thick); 11 - conditioned Quercus Cerris planks (40 mm thick); 12 conditioned Quercus Cerris purlin ( 80 x $80 \mathrm{~mm}) ; 13$ - conditioned glued laminated Quercus Cerris beam ( 200 x $250 \mathrm{~mm})$;

14 - wedge; 15 - conditioned glued laminated Quercus Cerris beam ( 200 × $250 \mathrm{~mm}$ ); 16 - stainless still beam base; 17 stainless still improved bond bar (Ø $16 \mathrm{~mm}$ ); 18 - non-vapor retardant roof underlay; 19 - vapor barrier glued to the vault and wall structure, and mineral wool insulation $(10 \mathrm{~cm}$ thick $)$

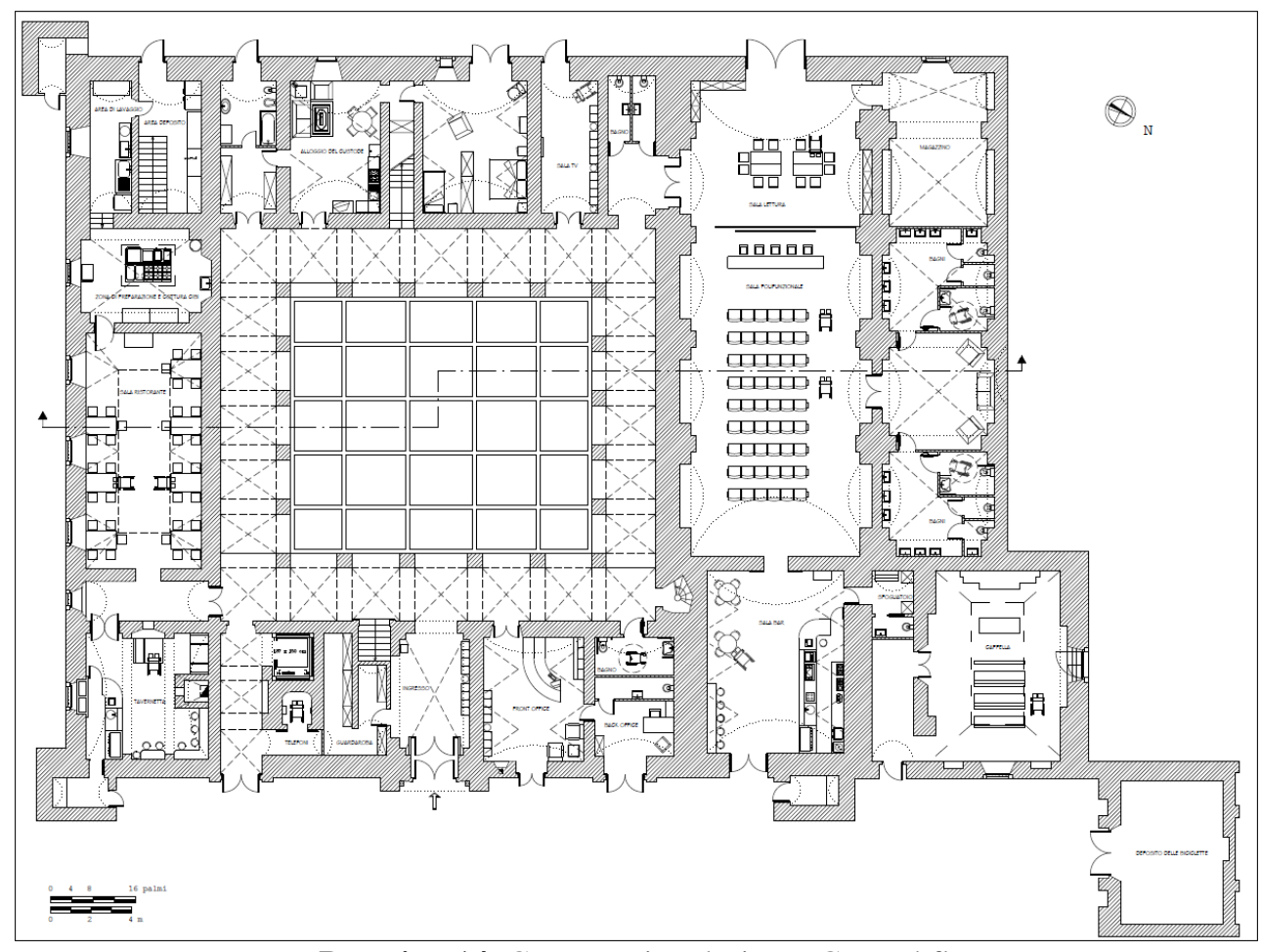

Drawing 14: Conservation design - Ground floor 


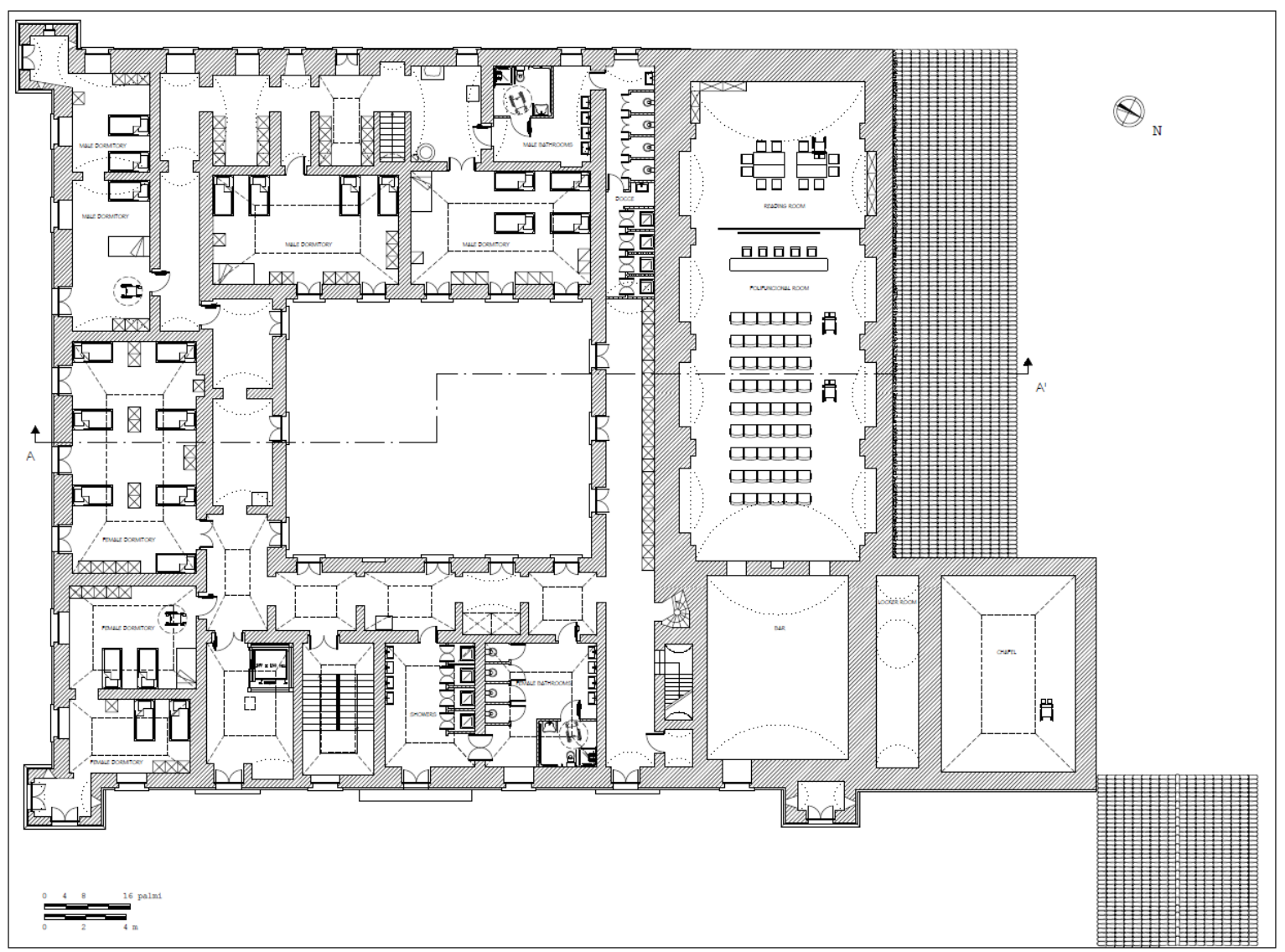

Drawing 15: Conservation design - First floor

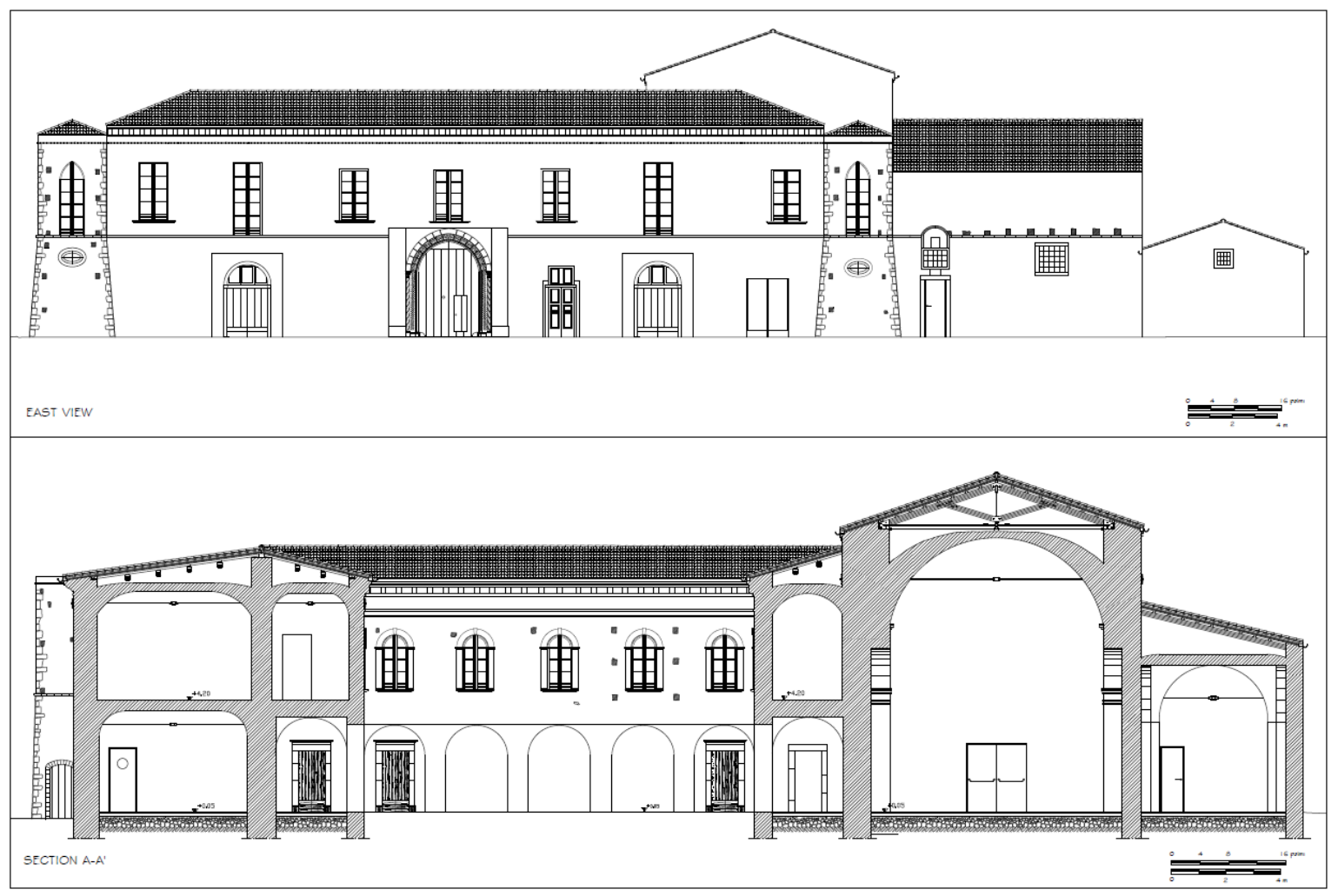

Drawing 16: Conservation design - East elevation and Section A-A' 
The seismic vulnerability of the building has been verified, through the methodology pointed out by the Authors, in the area of expertise of La.Te.C. - Constructions Technology Laboratory of the School of Engineering of Basilicata University - Potenza (Marino \& Lembo, 2017 [8]), and therefore before through Static Linear Analysis, using VM procedure (Dolce \& Moroni, 2005 [9]), and after though Static Non-Linear Analysis and Push-Over Analysis, using software CDMaWin 2014.

The results are the following. Upgrading walls resistance through colloidal lime grouts and fulfilling connections through tie beams to counteracting the vaults' thrust, it is possible to reach a ratio $\alpha$ of Seismic Vulnerability (ratio between Resistant Peak Ground Accelleration and Demand PGA) more than 70\% and then satisfactory. A further improvement could be reached through the use of a three-dimensional tying system, with pre-compressed stainless still ribbons (CAM system) (Marino \& Lembo 2017 [8]), but the Authors decided to not use it, both for economic reasons as in respect to the monumental character of the building. The use of the tie beams proves still to be the safer, more economic and easily reversible system for safeguard intervention, strengthening and restoration (see Draw. 17 and 18). To treat the crushing of Cloister's pillars, besides the emptying of the vaults of the first floor, it is scheduled the wrapping with carbon fibers, then rendered and colored.

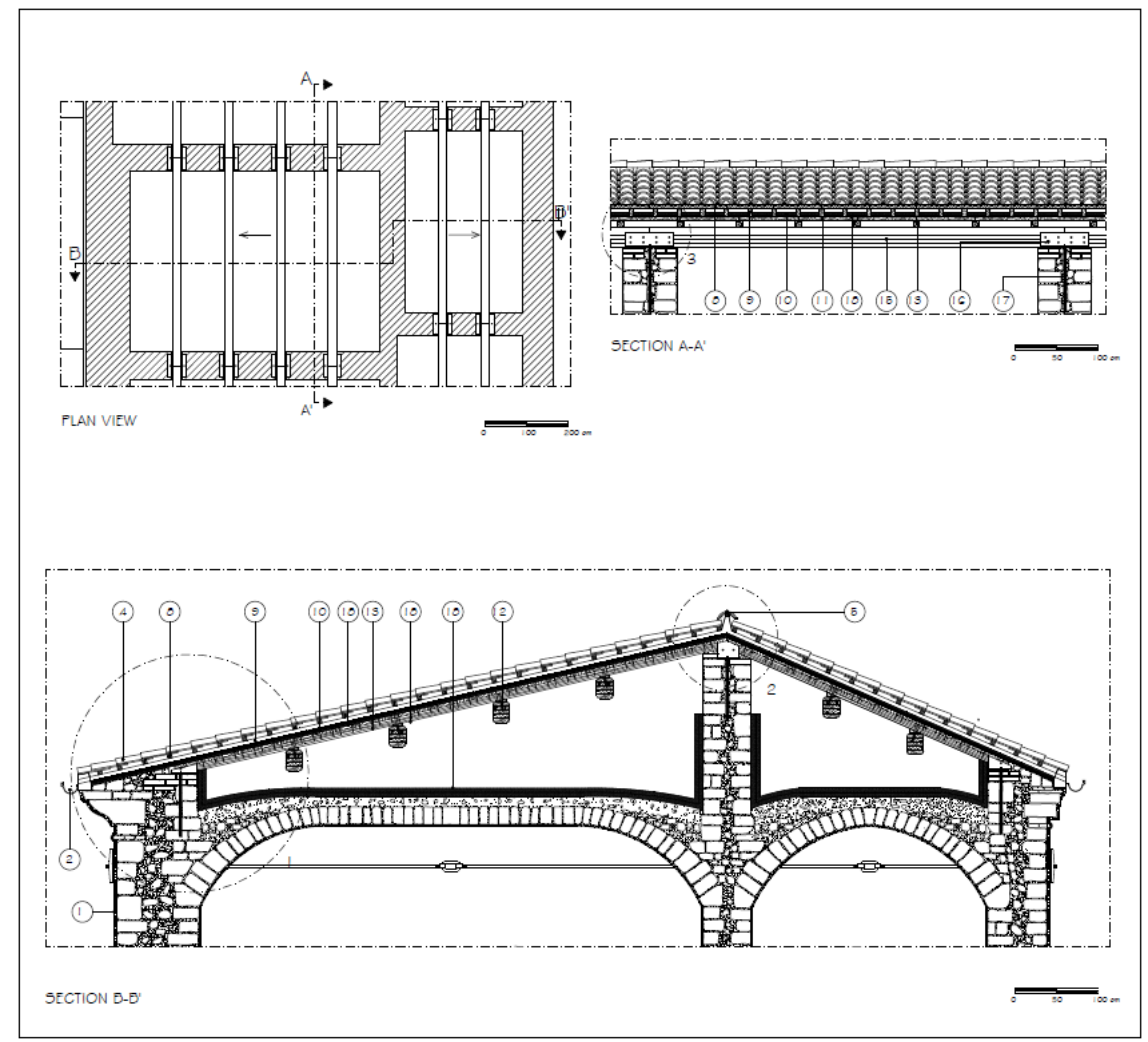

Drawing 17: Conservative design of typical roof

(Legend: 1 - thermo-insulating render $(40 \mathrm{~mm}) ; 2$ - copper gutter $(10 / 10 \mathrm{~mm}) ; 3$ - copper mesh; 4 - bent tile; 5 - ridge cap; 6 wood and copper ventilation element; 7 - copper fixing element for bent tile; 8 - counter batten $(50$ x $50 \mathrm{~mm})$; 9 - batten (50 x $100 \mathrm{~mm}) ; 10$ - cork insulating panels (30 +30 mm thick); 11 - conditioned Quercus Cerris planks (40 mm thick);

12 - s.s. still screw; 13 - conditioned Quercus Cerris purlin ( 80 x $80 \mathrm{~mm}) ; 14$ - wedge; 15 - glued laminated conditioned Quercus Cerris beam (200 x $250 \mathrm{~mm}) ; 16$ - s.s. beam base; 17 - s.s. improved bond bar (Ø $16 \mathrm{~mm}) ; 18$ - non-vapor retardant roof underlay; 19 - vapour barrier glued to the vault and wall structure, and mineral wool insulation (10 cm thick)

It is forecast the application on external walls of a mineral insulating render with $\lambda=0,052 \mathrm{~W} / \mathrm{mK}$, in the thickness of four centimeters for walls in which the render it isn't, and (subject to the application of a primer micro) in the thickness that is necessary for reaching four centimeters in the parts in which the render is yet present, in way to preserve integral documentation of the original render and colors: not much for reaching performances today scheduled for common buildings, but sufficient for earning the other half of useful thermal inertia, which today is dispersed in the exterior, and for being delighted as phase displacement and attenuation in summer time, which will be that of maximum attending of the structure (Cahiers CSTB, 1980 [10]); render reinforced with glass fiber mesh in the exterior third of the thickness. Frames and rails have been re-designed, similar to existing, but obviously with double glazing and efficient rabbets and gaskets (see Draw. 19 and 20). 


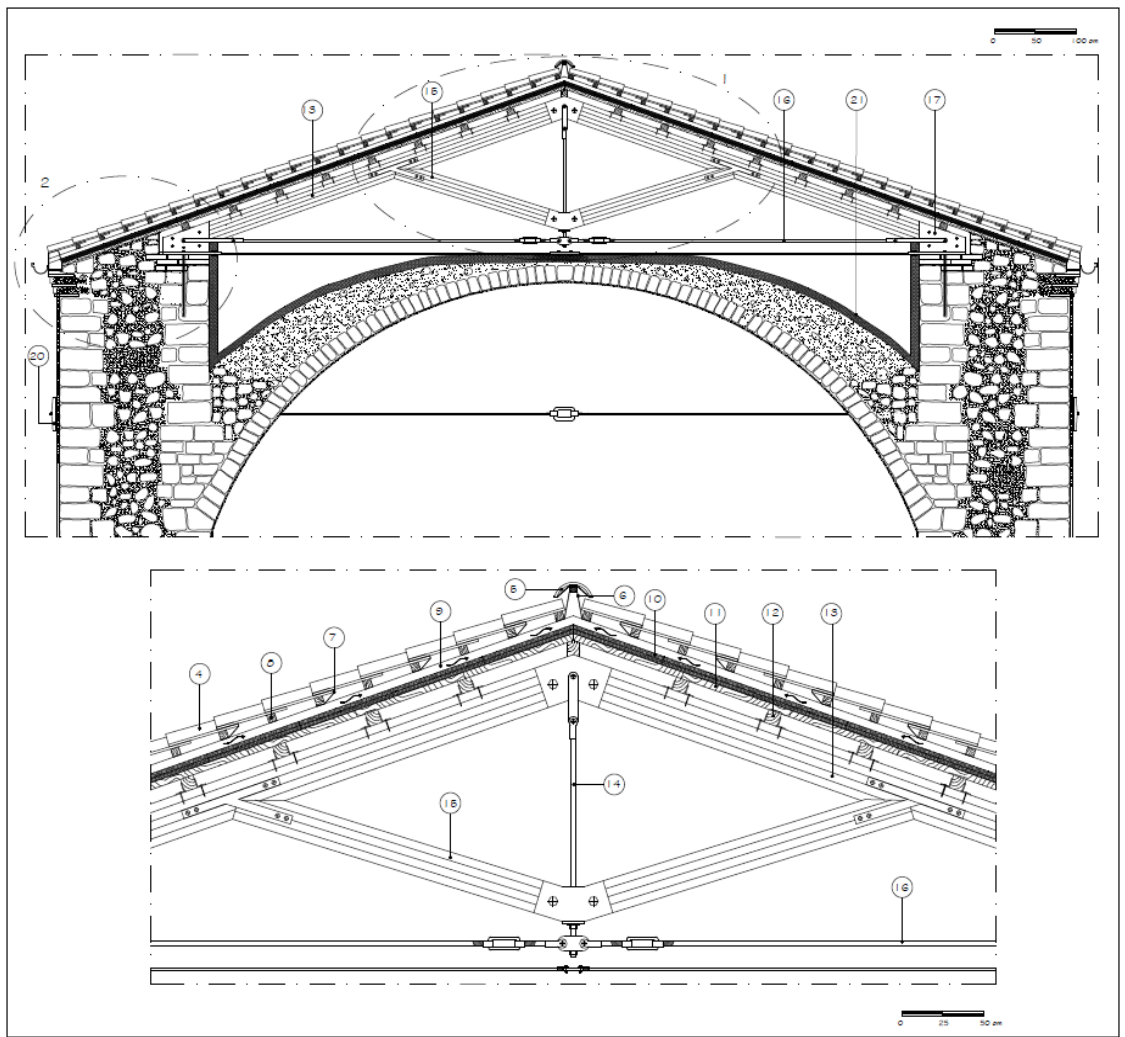

Drawing 18: Conservative design: roof on Church

(Legend: 1 - thermo-insulating render $(40 \mathrm{~mm}) ; 2$ - copper gutter $(10 / 10 \mathrm{~mm}) ; 3$ - copper mesh; 4 - bent tile; 5 - ridge cap; 6 - wood and copper ventilation element; 7 - copper fixing element for bent tile; 8 - counter batten (50 x $50 \mathrm{~mm}) ; 9$ - batten

(50 x $100 \mathrm{~mm}) ; 10$ - cork insulating panels $(30+30 \mathrm{~mm}$ thick); 11 - conditioned Quercus Cerris planks (40 mm thick);

12 - conditioned Quercus Cerris purlin $(80 \times 80 \mathrm{~mm} ; 13$ - conditioned glued laminated Quercus Cerris strut (200 x 250 $\mathrm{mm}) ; 14$ - stainless still king post (Ø $30 \mathrm{~mm}) ; 15$ - conditioned glued laminated Quercus Cerris knee rafter $(200 \times 200 \mathrm{~mm})$; 16 - stainless still tie beam $(\varnothing 30 \mathrm{~mm}) ; 17$ - stainless still king-post truss base; 18 - stainless still improved bond bar (Ø 18 $\mathrm{mm}) ; 19$ - stainless still tie rod (Ø20 mm); 20 - stainless still fixing plate, cast iron painted; 21 - vapor barrier glued to the vault and wall structure, and mineral wool insulation $(10 \mathrm{~cm}$ thick)

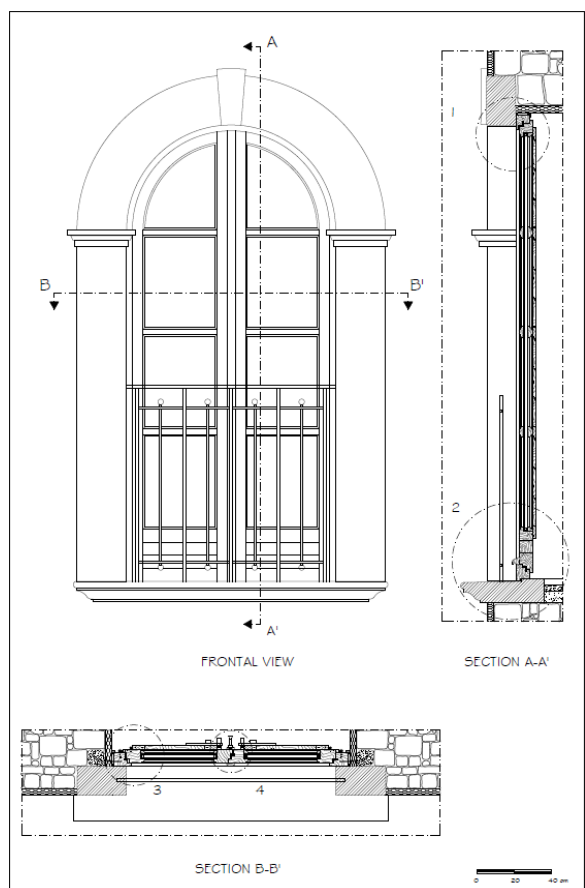

Drawing 19: Conservative design of new frames

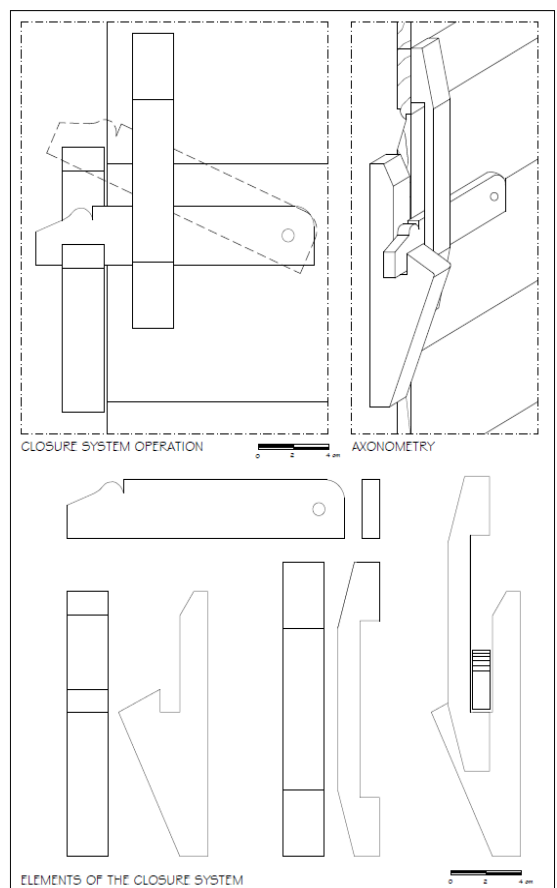

Drawing 20: Conservative design of new rails 
It is forecast to pose again the original floors in terracotta in the external and internal areas, conserving and/or refurbishing these surviving, and to re-apply the warm original coloring, peculiar of eighteenth-century tradition.

\section{Conclusions}

Cost of intervention has been allowed in 4,6 million euro, furnishings included; it is perfectly compatible with outlined objectives. It is demonstrated that intervening with building systems simplest and validated by tradition, following vocations of existing structures, with an attitude similar to that of judoka or samurai, rather than that of the Greek-roman wrestler or Templar, it is possible to reach the objectives of conservation and of increase in value of the material culture and of civilization tout-court of the Country.

\section{References}

[1] LEMBO FILIBERTO, The Angevin foundation and construction of the Franca Martina, in AA.VV. Martina Franca: a cultural island, Martina Franca, Puglia Region CRSEC TA/51 - Pugliesi Graphic Arts snc Eds., 1992, pp. $46-97$ (in Italian) [2] BERTAUX ÉMILE, The medieval monuments of the Vulture region, supplement to Naples Very Noble, VI, pp. XVIXVIII, 1897 (in Italian)

[3] MINISTRY FOR THE CULTURAL AND ENVIRONMENTAL HERITAGE OF THE BASILICATA, Franciscan settlements in Basilicata, Matera, Basilicata Editions, 1988, vol.1 (in Italian)

[4] MARCONI PAOLO, Matter and meaning - The question of architectural conservation, Roma - Bari, Gius. Laterza \& Figli SpA Eds.,1999 (in Italian)

[5] LICINIO RAFFAELE, Medieval castles. Puglia and Basilicata: from the Normans to Frederick II and Charles of Anjou, Bari, Caratteri Mobili Editor, 2010 (in Italian)

[6] LEISTIKOW DANKWART, Castles and palaces in the "Capitanata" of the XIII century, Foggia, Provincial Administration Editions, 1989 (in Italian)

[7] LEMBO F., MARINO F.P.R., Floors realized in Quercus Cerris laminated timber in buildings with structure in masonry, performing anti-seismic functions. in: Braj P. Sinha, Leyla Tanaçan (Editors), "ISSM08 - 8th International seminar on structural masonry", Congress Proceedings, Istanbul, 5-7 November 2008, Istanbul Technical University (Turkey), Çizgi Basim Yayin Ltd. Sti, 2008, pp. 441-448, ISBN: 978-975-561-342-0

[8] MARINO F.P.R., LEMBO F., How to define a design methodology able to achieve anti-seismic and functional upgrades of building heritage, in: Rogério Amoêda, Sérgio Lira \& Cristina Pinheiro (Eds.), "REHAB2017 - Proceedings of the 3rd International Conference on Preservation, Maintenance and Rehabilitation of Historical Buildings and Structures", Green Lines Institute (Publisher), Braga (Portogallo), Chapter 3: Preservation and rehabilitation of historic buildings and structures: case studies, 2017, pp. 309-321, ISBN: 978-989-8734-24-2, eBook ISBN: 978-989-8734-23-5

[9] DOLCE M., MORONI C., Evaluation of the vulnerability and seismic risk of public buildings using VC procedures (Reinforced Concrete Vulnerability) and VM (Masonry Vulnerability), Department of Structures, Geotechnics, and Geology applied to Engineering, University of Basilicata, Potenza, Department proc., 2005, Vol. 4/2005 (in Italian)

[10] CSTB BOOKS 1980, Examples of solutions to facilitate the application of the Regulation respecting the construction of residential buildings. Title IV. Summer comfort, CSTB Book n. 1648, may 1980 (in French)

(C) 2018 by the author(s). This work is licensed under a Creative Commons Attribution 4.0 International License (http://creativecommons.org/licenses/by/4.0/). Authors retain copyright of their work, with first publication rights granted to Tech Reviews Ltd. 